Ruhan AŞKIN UZEL

Yaşar Üniversitesi, Meslek Yüksekokulu, Gıda Teknolojisi Programı, 35100, İzmir / Türkiye sorumlu yazar: ruhan.uzel@yasar.edu.tr

Anahtar Sözcükler:

Beslenme, yeme tutumu, geleneksel mutfak kültürü, sağlıklı yaşam

Key Words:

Nutrition, eating attitude, traditional cullinary culture, healthy lifestyle

\section{Geleneksel Mutfak Kültürü ve Tarımsal Ürün Çeşitliliğinin, Üniversite Öğrencileri Beslenme Durumu Üzerine Etkisi}

\author{
The Effect of Traditional Culinary and Agricultural Product \\ Diversity on Nutrition Status of University Students
}

Alınış (Received): 15.06.2017～Kabul tarihi (Accepted): 06.07.2017

\section{ÖZET}

Y

aşama hazırlık ve olgunlaşma dönemi olarak bilinen, genellikle 18-25 yaş aralığındaki dönemi kapsayan üniversite çağında ev dışında daha çok beslenilmekte, bireyler beslenme biçimleri ve aktivitelerine ne yazık ki bunu yansıtmamaktadırlar. Yapılan çalışmanın temel amacı, üniversite öğrencilerinin geleneksel tarım çeşitliliği konusunda farkındalığını tespit etmek, yeme tutumlarını belirlemek, olası aksaklıkları kontrol altına alma yolları geliştirmek ve geleneksel mutfak kültürünün söz konusu beslenme tutumlarına olan etkisini incelemektir. Bu amaçla, Yaşar Üniversitesi'nde öğrenim gören 242 öğrencinin demografik sosyo-kültürel özellikleri, beslenmeye ilişkin davranışlarını değerlendiren bir anket formu ile $\mathbf{4 0}$ soruluk Yeme Tutum Testi (YTT) uygulanmış, Sağlıklı Yaşam Biçimi Davranışları Ölçeği (SYBDÖ) kullanılarak beslenme mevcut durumunun tespiti yapılmış ve bir gösterge çizelgesi geliştirilmiş̧ir. Söz konusu araştırmada yer alan sorularda aynı zamanda mutfak kültürüne ilişkin sınamalar da yapılarak örneklem grubunun beslenmesinde geleneksel değerlere eğilim olup olmadığı da ölçülmüşsür. Bu bağlamda, yaş ortalaması 20,6 olan öğrencilerin \% $\mathbf{6 5 , 7}$ sinin Vücut Kitle İndeksi (VKI) değerlerinin normal aralıkta olduğu saptanmıştır. \% 8,2'si diyet yapmakta olan öğrencilerin yeme tutumlarında aksaklıklar tespit edilmiş olup, öğrencilerin $\% 34,4^{\prime}$ ünde geleneksel mutfak kültüründen uzaklaşma olduğu gözlemlenmiştir. Bu da sağlıklı beslenmede geleneksel gıdalar konusunda farkındalığın yaratılması ihtiyacını, öğrencilerin yeme tutumlarının kontrol altına alınmasında geleneksel tipte beslenme sıklığııın arttıııması gerektiğini açıkça vurgulamaktadır.

\begin{abstract}
In the university studenthood, which is generally known as the preparation for life and maturity period between the ages of 18 and 25 , people eat outside more than at home and do not reflect these facts to their diet and activities. At this point it has been understood that the movement that embraces the consumption of healthy, traditional food materials for healthy life, should play an active role in establishment of an healthy life style. From this point of view, the aim of this study is to determine the eating attitudes of the university students, to control the malfunctions and to examine the effect of traditional culinary culture on the nutritional attitudes. For this purpose, a survey form evaluating demographic socio-cultural characteristics, nutritional behavior of the242 students studying at Yaşar University and a 40-item Eating Attitude Test (YTT) were applied and the current state of nutrition was determined by using the Healthy Lifestyle Behaviors Scale (SYBDL)and an indicator chart has been developed. At thesame time, the questionnaires related to the culinary culture were also conducted to determinewhethertherewas atendency to traditional values or not. In this context, it was determined that $65.7 \%$ of the students with a meanage of $\mathbf{2 0 . 6}$ had normal body massindex (BMI) values. It was also observed that the eating habits of students who were in diet by $8.2 \%$ were found to be disturbed and $34.4 \%$ of the students were seemed to be away from the values of traditional culinary culture. This clearly emphasizes the need to create awareness about traditional foods in healthy diet and to increase the frequency of traditionalty pefeeding in order to control the eating habits of university students.
\end{abstract}




\section{Giriş}

Mutfak kültürü kavramı beslenmeyi sağlayan yiyecek ve içecek kültürünün, hazırlanma, pişirme, saklama ve tüketim süreçlerinin, aynı zamanda bu süreçte kullanılan araç-gereçlerin derlenerek oluşturduğu bir kültürel yapıyı anlatır (Öğel, 1991). Her milletin, ülkenin ve toplumun sosyo-kültürel ve ekonomik yapısına, tarihsel kimliğine, beslenme alışkanlıklarına, damak zevkine, tarımsal üretim ve yapısına göre şekillenmiş bir mutfağı vardır.

Tarım, zirai ürün profili, ürünlerde oluşan farkındalık ve farklı kullanım alanları ile birlikte bütünüyle beslenme ve yaşam biçimimizi etkileyen bir olgudur. Tarımsal ürün çeşitliliği ve bu çeşitliliğin her yaş grubunda belirli oranlarda oluşturduğu algı ve benimsenmişlik düzeyi üzerinden beslenme düzeninin oturtulmuş olduğu yadsınamaz bir gerçektir. Türk toplumunun yeme içme alışkanlıklarına bakıldığında, tarımsal yapının etkili olduğu görülmektedir. Et, süt ürünlerinin yemek çeşitlerinde baskınlığı; sebze-ethububat ürünlerinin birlikte pişirilmesi, kahvaltıda tercih edilebilen çorbalar tarımsal ve göçebe kültürün eskiden gelen ve günümüze yansıyan etkileridir. Tarımsal yapının etkisi aynı zamanda hamur işleri çeşitliliğinin fazlalığında da kendini göstermektedir. Bu hususta, tarımsal ürünlere olan hâkimiyet, pişirilen yemeklerde bu ürünlerin kullanımı ve beslenmede bilinçli miktarlarda tüketilmesi gibi hususlar dikkatle ele alınması gereken konulardandır. Bu faktörlerden hareketle, günümüzde beslenme ilkeleri ne yazık ki toplumun çoğunluğu tarafından sağlıklı ve bilinçli bir şekilde uygulanamadığı dikkati çekmektedir (Sucaklı, 2015). Yeme bozuklukları (YB) bireylerin sadece fiziksel görünümlerindeki olumsuzlukların ön planda olduğu bir durum değil, aynı zamanda bireyleri psikolojik olarak da olumsuz etkileyebilecek bir durumdur. Literatürde, bir hastalık olarak tanımlanan yeme bozukluğu psikiyatrik hastalarında ölüm oranı gün geçtikçe artmaktadır (Vardar ve Erzengin, 2011). Yeme bozukluğu hakkında yapılan araştırmalar, duruma neden olan etmenlerin arasında bireylerin gelişim sürecindeki kişisel, çevresel ve sosyal etmenlerin rol oynadığını sergilemiştir (Öztürk, 2004).

Yeme bozukluklarının görüldüğü yaş grupları incelendiğinde, riskin büyük olduğu grubun yığılmalı olarak üniversite öğrencileri olduğu görülmektedir. Aslında yeme bozuklukları sadece Türkiye'de değil, Dünya genelince baş edilmesi gün geçtikçe zorlaşan bir durum haline gelmiştir (Polat ve ark., 2005). Yaşama hazırlık ve olgunlaşma dönemi olarak bilinen beliren yetişkinlik dönemindeki (18-25 yaş) üniversite öğrencisi olan bireyin yaşam biçiminde bazı değişiklikler görülür.
Ancak bu değişikler, stres yönetimi (gelecek kaygıları, sınırları zorlayıcı davranışlar, şiddet), kendi sağlıklarının sorumluluğunu alamama (sigara, alkol ve uyuşturucu kullanımı), kötü beslenme (ayaküstü atıştırma, yetersiz beslenme) gibi riskli sağlık davranışlarını da beraberinde getirmektedir (Baban, 2010; Cohn ve ark., 1999; Sapmaz ve Yercan, 2015). Beliren yetişkinlik döneminde ev dışında daha çok beslenilmekte, bireyler besin seçimi ve aktivitelerin önemi ile ilgili gerçekleri bilmelerine karşın beslenme biçimleri ve aktivitelerine ne yazık ki bunu yansıtmamaktadırlar.

Bu yaş grubu öncesine bakıldığında, aslında önceki dönemlerden gelen aksaklıkların daha da büyük boyuta ulaşarak ciddi neticeleri işaret ettiği anlaşıımaktadır. Önceki dönemlerden yaklaşım yapıldığında, ailevi değerlerin baskın olduğu ve geleneksel yemek kültürünün aşılanabileceği dönem olan çocukluk dönemi ele alınabilir. Bu dönemde ailenin benimsediği yaşam ve yemek yeme tarzı ön planda olduğu için çocukluk dönemi yeme alıskanlıklarının şekillenebileceği en elverişli dönemlerden birisi olmaktadır. Oysaki ergenlik döneminde bireyin kendi tercihleri ön planda tutulmaya başlanacak olup çevresel, bireysel ya da toplumsal nedenlerden biri ya da birkaçı sebebi ile yanlış kurulabilecek yeme tutum ve davranışı sonraki yıllarda önüne geçilemeyecek halde ciddi bozukluklara yol açabilecektir. Bireylerin bedensel gelişimlerinin hızlı olduğu, duygusal değişimlerin de ani dalgalanmalar şeklinde oluşacağı bu dönemde fazla kilodan kaynaklanabilecek vücut şekil bozukluğu önemli hasarlar bırakabilmektedir (Menteş ve ark., 2011). Buradan hareketle edinilen yanlış yeme tutum ve davranışı durumun en belirgin olduğu üniversite çağı ve devamındaki yetişkinlik döneminde bireysel sağlığın ve toplumsal ilişkilerin zedelenmesine neden olacak bir tehdit unsuru haline gelmektedir (Baş ve ark., 2005).

Günümüz çağının imkânları göz önünde bulundurulduğunda, bireylerin beslenme durumu ile ilişkili olan fazla kilo ve kronik rahatsızlıklarla mücadele için klinik metotlara ilaveten multidisipliner çalışmaların yapılması gerektiği, aktarılması gereken bilgilerin yaşam tarzı olarak benimsenmesi kaçınılmaz bir ihtiyaç haline gelmiştir. Konu ile ilgili olarak Dünya Sağlık Örgütü'nün 2004 yılında besin endüstrisine sağlıklı beslenmeyi destekleyecek uygulamalar için eylem çağrısında bulunduğu "Fiziksel Aktivite ve Sağlık ile Illişkili Küresel Stratejiler" bildirgesi de bulunmaktadır. Belirlenen hedeflere ulaşmadaki en stratejik yaklaşım, hedef kitlenin seçiminin ve durum tespitinin doğru yapılması; ölçüm ve kontrol yollarının uygun olarak verilmesidir. Yapılan çalışmalarda üniversite öğrencilerinin (Hui, 2002; Haddad ve ark., 2004; Ayaz ve ark., 2005) sağlıkl 
yaşam biçimi davranışlarını geliştirebilme konusuna yeterince önem vermediği saptanmıştır. 18-25 yaş üniversite öğrencileri grubu da en geniş grubu oluşturmaktadır. Bu nedenle çalışmanın hedef grubu olarak önceliklendirilmiştir.

Bu önemli hususlardan hareketle söz konusu çalışma, 18-25 yaş üniversite öğrencilerinin vücut kitle indeksi değerlerinden yola çıkılarak beslenme tutumlarını tespit etmek, beslenme şekillerindeki aksaklıkları kontrol altına alarak geleneksel beslenme kıstaslarının gözetildiği bir düzenlemede farkındalık oluşturmak, sağlıklı bir beslenme düzeni oluşturulmasında geleneksel tipte beslenmenin hedef yaş grubundaki yeri ve benimsenme seviyesi hakkında incelemede bulunmak amacı ile yapılmıştır. Bu amaca yönelik olarak Yaşar Üniversitesi öğrencileri temsili grup olarak belirlenmiştir. Öncelikle bireylerin beslenme durumları bilimsel yöntemler kullanılarak tespit edilmiş olup, ardından, beslenme şekilleri ve yaşam biçimleri arasında inceleme yapılmış, etki eden faktörler etraflıca ele alınarak elde edilen bulguların genel veriler ışı̆̆ında karşılaştırmalı yorumlaması yapılmış̦tır.

\section{MATERYAL ve YÖNTEM}

Araştırma kapsamında seçilen öğrenci kitlesi, kullanılan yöntem, verilerin analizi, araştırma sonuçları aşağıdaki şekilde belirtilmiştir.

\section{Evren ve örneklem}

Çalışma evreni, veri toplanan hedef kitledir, başka bir ifade ile araştırmanın sonuçlarının bütünleştirilebilmesi için seçilen uygun sayıdaki veri adetidir (Altunışık ve ark., 2007; Karasar, 2004). Buna göre, yapılan araştırmanın evreni Yaşar Üniversitesi Meslek Yüksekokulu öğrencileri olup, örneklem büyüklüğü 242 kişi olarak belirlenmiştir.

\section{Veri toplama materyali, içeriği ve analiz metodu}

Yapılan araştırma kesitsel türde olup Yaşar Üniversitesi Meslek Yüksekokulu öğrencileri ile OcakMart 2017 tarihleri arasında yürütülmüştür. Örneklem grubu üzerinden planlanan aşamada Yaşar Üniversitesi Meslek Yüksekokulu Etik Kurulı'ndan alınan izin sonrasında, çalışmanın evrenini oluşturan Yaşar Üniversitesi Meslek Yüksekokulu'nda öğrenim gören ve araştırmaya katılmayı gönüllü olarak kabul eden öğrenciler içinden, tesadüfi örneklem yöntemi ile seçilen, 18-25 yaş arasındaki 242 öğrenci ile çalışılmıştır. Örneklem büyüklüğü evren birey sayısı bilinen gruplarda örnek büyüklüğü hesaplama formülünden $\mathrm{n}=\mathrm{Nt}^{2}(\mathrm{pq}) / \mathrm{d}^{2}(\mathrm{~N}-1)+\mathrm{t}^{2}(\mathrm{pq})$ yararlanılarak (N: anakütle büyüklüğü, $n$ : örneklem büyüklüğü, p: ilgilenilen olayın görülme olasılığı, q: ilgilenilen olayın görülmeme olasılığı, d: kabul edilen \pm örnekleme hata oranı, t: t tablosu kritik değeri; $\mathrm{t}=1.96, \mathrm{~d}=0.03, \mathrm{p}=0.15$ ) hesaplanmıştır. Saptanan örneklem büyüklüğü \%10 arttırılarak ulaşılması hedeflenen öğrenci sayısı belirlenmiştir. Bu kapsamda toplamda 267 öğrenciye ulaşılmış olup araştırmacılar tarafından hatalı ve eksik doldurulduğu tespit edilen 25 adet anket çalışma dışı bırakılarak analizler yapılmıştır.

Araştırma kapsamında veri toplama yöntemi olarak; öğrencilerin yaş, cinsiyet gibi demografik özelliklerini ve boy uzunluğu ve vücut ağırlığını içeren antropometrik ölçüm bilgilerinin yer aldığı anket formu ve Yeme Tutum Testi (YTT-40) kullanılmıştır.

Demografik özelliklerin tespit edilmesinde kullanılan bölümde toplam 15 adet soru bulunmaktadır. İlk 9 soru öğrencilerin boyu, kilosu, cinsiyeti, medeni durumu, eğitim gördüğü program, sınıfı gibi temel özellikleri ölçme odaklıdır. Geriye kalan 6 soru ise doğum yeri, ekonomik durumu, ailedeki birey sayısı, temel öğünlerin önemi gibi sosyo-demografik açıdan yemek yeme kültürünün tespitine yönelik sorulardan meydana gelmiştir.

Araştırmanın ikinci kısmını oluşturan 40 soruluk yeme tutum testi (YTT-40) kapsamında ise detaylı olarak yemek yeme alışkanlıklarına yönelik sorular bulunmaktadır. Öğrencilerin yemek yeme ile ilgili davranış ve tutumları, varsa aksaklıkların belirtilerinin tespit edilmesine yönelik sorular yer almaktadır. YTT-40 testi fiziksel olarak bireylerde beslenme tutum aksaklıklarını belirleyebileceği gibi, "hasta" olarak tanımlanan, hedef grubundaki öğrencilerin psikolojik olarak aksaklık yaşayıp yaşamadıklarının anlaşılması için kullanılmıştır (Button ve Whitehouse, 1981; Patton ve ark., 1990).

Yeme TutumTesti (YTT-40) 6 dereceli (Daima, Çoksık, Sıksık, Bazen, Nadiren, Hiçbir zaman) Likert tipi yanıtlanan özbildirime dayalı bir ölçektir. Değerlendirmenin kolay yapılabilmesi için doğrusal sıralama yapılmış olup 1 sayısı daima cevabını, 6 sayısı ise hiçbir zaman cevabını simgelemiştir. On bir yaşından büyük kişilere uygulanabilen, yeme bozukluğu olan ergenleri belirlemek ve anoreksiyanervoza belirtilerini ölçmek amacıyla Garner ve Garfinkel (1979) tarafından geliştirilmiş, Türkiye'de bu ölçeğin Türkçeye uyarlanması Savaşır ve Erol (1989) tarafından yapılmıştır. Maddelerden 1, $18,19,23,27,39$ için bazen 1 puan, nadiren 2 puan ve hiçbir zaman 3 puan ve diğer seçenekler 0 puan olarak değerlendirilmiştir. Ölçeğin diğer maddeleri için ise daima 3 puan, çoksık 2 puan ve sıksık 1 puan ve diğer seçenekler 0 puan olarak hesaplanmıştır. 
Sonuçta ölçeğin her bir maddesinden alınan puanlar toplanarak ölçeğin toplam puanı elde edilmiştir. YTT testinin kesme noktası 30 puandır. 30 puan ve üzerinde alan kişiler yeme bozukluğu bulunma riski yüksek kişiler olarak değerlendirilmiştir. Puan artışı doğrudan patolojinin şiddeti ile ilişkilendirilmiştir.

Dünya Sağlık Örgütü'nün obezite sınıflandırması (<18,5: zayıf, 18,5-24,9: normal, 25,0-29,9: şişmanlık öncesi, 30,0-34,9: 1. derece obez, 35,0-39,9: 2. derece obez, >40: morbid obez) esas alınarak; katılımcıların özbildirimleriyle elde edilen vücut ağırlığı ve boy uzunluğu bilgilerinden "Vücut Ağırlığı/(Boy uzunluğu)2 $\left(\mathrm{kg} / \mathrm{m}^{2}\right)^{\prime \prime}$ formülü ile öğrencilerinVücut Kitle İndeksi (VKi) değeri hesaplanmıştır (Andreoli ve ark., 1997). Elde edilen veriler bilgisayar ortamına aktarılarak, Statistical Package for the Social Sciences (SPSS) for Windows 11.0 yazılımı aracılığı ile analizedilmiştir. Sonuçlar yüzde olarak belirtilmiş, sıklık ve Pearson ki-kare testleriyle değerlendirilmiş, $\mathrm{p}<0.05$ düzeyi istatistiki açıdan anlamlı kabul edilmiştir.

\section{ARAŞTIRMA BULGULARI ve TARTIŞMA}

18-25 yaş aralı̆̆ındaki üniversite öğrencilerinin yemek yeme tutumlarının tespit edilmesi ile beslenme durumları hakkında bilgi veren ve geleneksel yemek kültürüne eğilimlerinin test edildiği araştırma, örnek çalışma olarak Yaşar Üniversitesi Meslek Yüksekokulu'nda yürütülmüştür. Elde edilen bulgular aşağıdaki şekilde belirtilmiştir.

\section{Araştırmaya katılan öğrenciler hakkında tanıtıcı bilgiler}

Bu bölümde öğrencilerin Yaşar Üniversitesi Meslek Yüksekokulu'nda öğrenim gördüğü programın ismi ile sosyo demografik özelliklerini belirlemeye yönelik sorular yöneltilmiştir. Demografik yapıya ilişkin bulgular Çizelge 1'de verilmiştir.

Buna göre öğrencilerin \%52,48'i kız, \%47,52'si erkektir. Öğrenciler, \%50,83 oranla en çok 20-21 yaş aralığında olmakla beraber \%96,52 oranında bekârdır. Öğrencilere ekonomik durumlarına ilişkin farklı durum derecelendirmesine göre sorular yöneltilmiş, elde edilen cevaplarda \%59,92'sinin (135 kişi) rahatça harcama yapabildikleri, \%31,4'ünün (76 kişi) ihtiyaçlarını karşılamak için harcama yapabildiği, \%7,85' inin (19 kişi) zorunlu ihtiyaçları karşılayabildiği belirtilmiştir. \%2'lik bir kısmın ise zorunlu ihtiyaçları dahi karşılamada sıkıntı yaşadığı tespit edilmiştir. Ekonomik durumu iyi olan öğrencilerin besin materyallerine ulaşma konusunda sıkıntı yaşamadıkları, bilinçli gıda tüketimi konusunda standartları yakalayabildikleri gözlemlenmiştir. Yine araştırmaya katılan öğrencilerden alınan yanıtlara istinaden Yaşar Üniversitesi Meslek Yüksekokulu programlarına göre dağılımları Çizelge 2'te verilmiştir.

Çizelge 1. Araştırmaya katılan öğrencilerin demografik özellikleri Table 1. Demographic characteristics of students participating in the survey

\begin{tabular}{|l|c|c|}
\hline Cinsiyet & Sayı & Yüzde \\
\hline Erkek & 127 & 52,48 \\
\hline Kız & 115 & 47,52 \\
\hline Toplam & 242 & 100,00 \\
\hline Yaş & Sayı & Yüzde \\
\hline $18-19$ & 42 & 17,35 \\
\hline $20-21$ & 123 & 50,83 \\
\hline $22-23$ & 62 & 25,62 \\
\hline 24 ve üzeri & 15 & 6,20 \\
\hline Toplam & 242 & 100,00 \\
\hline Ekonomik Durum & Sayı & Yüzde \\
\hline Rahatça harcama & 145 & 59,92 \\
\hline intiyaçları karşılama & 76 & 31,4 \\
\hline Sadece zorunlu ihtiyaçları karşımama & 19 & 7,85 \\
\hline Zorunlu ihtiyaçları dahi karşıyamama & 2 & 0,83 \\
\hline Toplam & 242 & 100,00 \\
\hline Medeni Durum & Sayı & Yüzde \\
\hline Bekâr & 233 & 96,52 \\
\hline Evli & 9 & 2,48 \\
\hline Toplam & 242 & 100,00 \\
\hline
\end{tabular}

Çizelge 2. Öğrencilerin öğrenim gördükleri programların dağılımı Table 2. Distribution of students' programs

\begin{tabular}{|l|c|c|}
\hline Programın Adı & Sayı & Yüzde \\
\hline Alternatif Enerji Kaynakları Teknolojisi & 18 & 7,44 \\
\hline Bankacılık ve Sigortacılık & 5 & 2,10 \\
\hline Bilgisayar Programcılığı & 17 & 7,03 \\
\hline Deniz ve Liman İşletmeciliği & 13 & 5,37 \\
\hline Dış Ticaret & 40 & 16,52 \\
\hline Gıda Teknolojisi & 34 & 14,02 \\
\hline Grafik Tasarımı & 21 & 8,70 \\
\hline Halkla İlişkiler ve Tanıtım & 42 & 17,36 \\
\hline Lojistik & 34 & 14,05 \\
\hline Marina ve Yat Iş̧letmeciliği & 13 & 5,38 \\
\hline Turizm ve Otel İşletmeciliği & 5 & 2,07 \\
\hline Toplam & 242 & 100,00 \\
\hline Sınıfı & Sayı & Yüzde \\
\hline $\begin{array}{l}\text { 1. sınıf } \\
\text { 2. }\end{array}$ & 52 & 21,48 \\
\hline 3. sınıf & 183 & 75,62 \\
\hline Artık yıl & 7 & 2,90 \\
\hline Toplam & 242 & 100,00 \\
\hline
\end{tabular}

Çizelge 2'den anlaşıldığı üzere, ankete katılan 11 farklı program öğrencisinden, en çok katılım sırası ile $\% 17,21$ ile Halkla Illişkiler ve Tanıtım, \%16,61 ile Dış Ticaret, \%14,23 ile Lojistik ve \%14,02 ile Gıda Teknolojisi Programlarından olmuştur. Öğrencilerin okudukları sınıflar ele alındığında \%21,48 oranla 1.sınıf, $\% 75,62$ oranla $2 . \sin$ if ve $\% 2,90$ oranla artık yıl öğrencileri oldukları belirlenmiştir. 
Öğrencilerin \%60,2'si İzmir ve çevresi doğumlu olup, \%71,1 oranında ise doğumdan itibaren İzmir'de ve $\% 49,2$ oranında 4 kişi olarak, $\% 81$ oranında ise aile ile birlikte yaşamakta oldukları belirtilmiştir. Buradan da yemeklerin aile düzeni içerisinde pişirilme şansının fazla olduğu, bireylerin geleneksel tipte beslenmeye aile ve kültür bakımından yatkın olabileceği kanısına varılmaktadır.

Öğrencilere günlük yemek yeme alışkanlıkları hakkında sorular yöneltilmiştir. Öğrencilerin \%56,2'si kahvaltının öneminin farkında olduğu görülmüştür. Ek olarak, \%7'si kahvaltı, öğle yemeği ya da akşam yemeğinden sadece 1 öğün; \%31,8'i 2 öğün; \%40,5'i 3 öğün yemek tüketmekte olduğu görülmüştür. Bir günde ara öğünler ile birlikte 4 ve daha fazla sayıda öğün tüketen kısım öğrencilerin \%20,7'sini oluşturmaktadır. Tespit edilen bu oran, tek öğünün esas alındığı sağlıksız bir beslenme düzeninin az olarak tercih edildiği, ideal olan en az 3 öğün yaklaşımının ise azımsanmayacak bir oranda görüldüğünü işaret etmektedir. Elde edilen sonucun YTT-40 testi verileri ile teyidi detaylı olarak alınmış ve sonraki bölümlerde yorumlanmıştır.

\section{Öğrencilerin tarımsal ürün çeşitliliği algısı ve yeme tutumları ile ilgili bulgular}

Beslenme kültürünün benimsenmesi ve uygulanması konusunda tarımsal farkındalığın ve ürün çeşitliliğinin bilinmesinin etkili olup olmadığı konusunda yöneltilen sorulara, öğrencilerde \%60 çoğunlukla kesinlikle etkili olduğu görüşü oluşmuştur. Bu oranı \%25 payı ile evet, $\% 11$ payı ile kısmen cevapları takip etmiş olup tarımsal ürün çeşitliliğin beslenme kültürü üzerine etkili olmadığını düşünen birey sayısı sadece \%4'tür (Şekil 1).

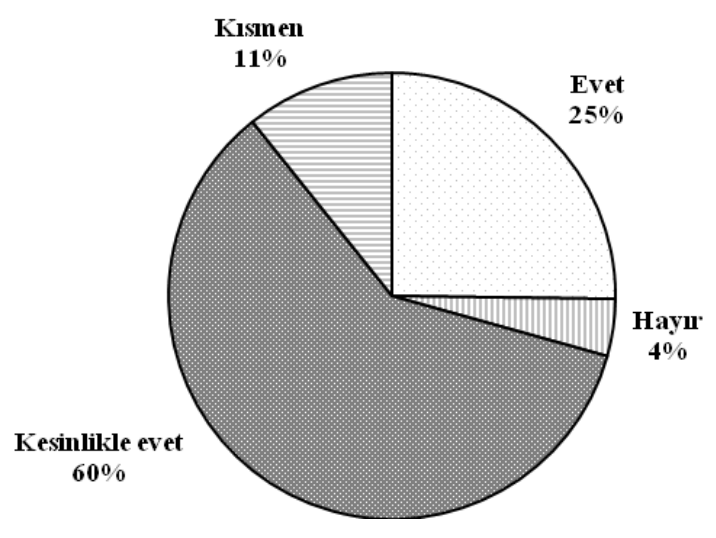

Şekil 1. Beslenme kültürü üzerine tarımsal farkındalığın etkisi Figure 1. Effect of agricultural awareness on nutrition culture

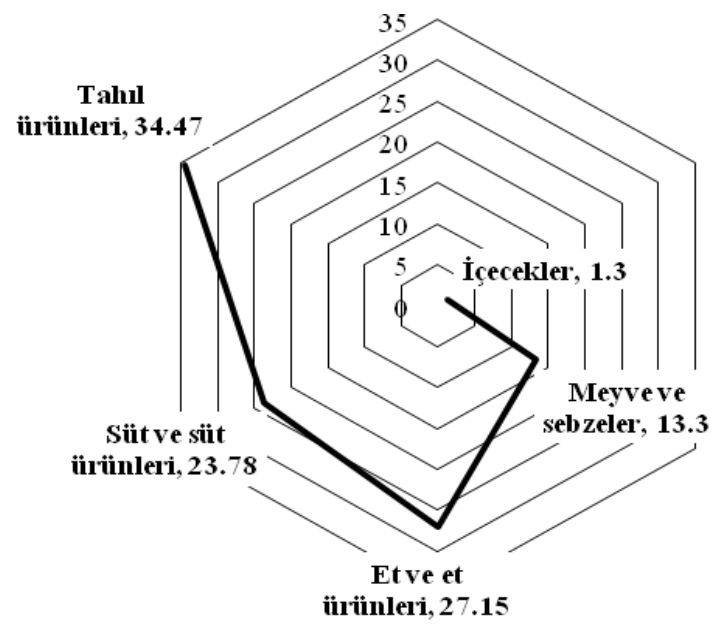

Şekil 2. Farklı tarım ürün gruplarının beslenme durumu üzerine etkisi

Figure 2. Effect of different agricultural product groups on nutritional status 
Ek olarak, her tarım ürününün diyette sağlıklı beslenme öğesi olarak yer alabileceği yorumu alınmıştır. Elde edilen geri bildirimden yola çıkılarak tarım ürün grupları öğrencilere sunulmuş ve bu besinlerin sağlıklı bir yeme tutum alternatifi olarak yapılandırılıp yapılandırılmamasına uygunluk sorulmuştur. Alınan cevaplarda, faydası olan yiyecek gruplarından kilo yapacağı endişesi ile diyette yer almaması gerekenlere işaret edildiği tespit edilmiştir. Şekil 2'de verilen dağılımdan da anlaşılacağı üzere, öğrencilerden \%34,47 ve \%27,15'i faydalı olduğunu bilmesine rağmen sırasıyla tahıl ve et grubu ürünlerinin diyette yer almaması gerektiğini düşünmektedir. Hâlbuki belirtilen gruplar beslenmenin temel unsurlarını teşkil etmektedir. Bu durum, toplumda tarımsal ürünler konusunda farkındalık olduğunu, ancak geleneksel tarım kültürü çeşitliliğinin ve faydalarının daha etkin bir biçimde vurgulanarak beslenme planlarında yer alması gerektiğini vurgulamaktadır.

VKI değerlerine göre; kız öğrencilerden $\% 15,75$ 'inin $(n=20)$ zayif $(<18,5), \% 76.38^{\prime}$ inin $(n=97)$ normal $(18,5-$
$24,9)$ ve $\% 7,87$ 'sinin ( $n=10)$ şişmanlık öncesi (pre-obez) $(25,0-29,9)$ olduğu tespit edilmiştir. Erkek öğrencilerden $\% 2,61$ 'inin ( $n=3)$ zayıf, \%69,57'sinin ( $n=80)$ normal, $\% 22,61$ 'inin ( $n=26)$ şişmanlık öncesi (pre-obez), $\% 4,35^{\prime}$ inin $(n=5)$ 1.derecede obez, \%0,87'sinin $(n=1)$ 2.derecede obez olduğu belirlenmiştir. Sonuçlardan da anlaşılacağı üzere öğrencilerin cinsiyetleri ile VKi değerleri arasındaki farkın anlamlı $(p<0.05)$ olduğu bulunmuştur. Erkek öğrencilerde, şişmanlık öncesi (preobez) öğrencilerin sayısının kız öğrencilerden daha fazla, normal öğrenci sayısının ise kız öğrencilerden daha az olduğu görülmüştür (Çizelge 3 ).

YTT-40 ölçeğinin değerlendirilmesine göre; öğrencilerin $\% 12,8^{\prime}$ inin ( $n=33$ ) puanının $\geq 30$ olduğu ve bu sebeple yeme davranışı bozukluğuna yatkınlıklarının olduğu ortaya çıkmıştır. Öğrencilerden \%8,6'sının $(n=21)$ YTT-40 puanı 30-40 arasında, \%3, $5^{\prime}$ inin $(n=11)$ YTT-40 puanı 41-46 arasında iken; 1 kişinin $(\% 0,2)$ YTT40 puanı 75 olarak bulunmuştur (Çizelge 4).

Çizelge 3. Öğrencilerin cinsiyetlerine göre VKi değerleri dağıımı

Table 3. Distribution of BMI values according to the gender of the students

\begin{tabular}{|c|c|c|c|c|c|c|c|c|c|c|}
\hline \multirow{3}{*}{ Cinsiyet } & \multicolumn{10}{|c|}{ VKi Değeri } \\
\hline & \multicolumn{2}{|c|}{$\begin{array}{l}<18,5 \\
\text { (zayıf) }\end{array}$} & \multicolumn{2}{|c|}{$\begin{array}{l}18,5-24,9 \\
\text { (normal) }\end{array}$} & \multicolumn{2}{|c|}{$\begin{array}{c}25,0-29,9 \\
\text { (șişmanlıköncesi, pre-obez) }\end{array}$} & \multicolumn{2}{|c|}{$\begin{array}{c}30,0-34,9 \\
\text { (1.derecede obez) }\end{array}$} & \multicolumn{2}{|c|}{$\begin{array}{c}35,0-39,9 \\
\text { (2.derecede obez) }\end{array}$} \\
\hline & $\mathbf{n}$ & $\%$ & $\mathbf{n}$ & $\%$ & $\mathbf{n}$ & $\%$ & $\mathbf{n}$ & $\%$ & $\mathbf{n}$ & $\%$ \\
\hline$K ı z(n=127-\% 52,48)$ & 20 & 15,75 & 97 & 76,38 & 10 & 7,87 & - & - & - & - \\
\hline Erkek(n=115-\%47,52) & 3 & 2,61 & 80 & 69,56 & 26 & 22,61 & 5 & 4,35 & 1 & 0,87 \\
\hline $\operatorname{Toplam}(n=242-\% 100)$ & 23 & 7,24 & 177 & 73,26 & 36 & 14,28 & 5 & 4,35 & 1 & 0,87 \\
\hline
\end{tabular}

Çizelge 4. Yeme davranışı bozukluğuna yatkınlığı olan öğrencilerin cinsiyetlerine göre YTT-40 puanları dağılımı Table 4. Distribution of YTT-40 scores according to the genders of students with a predisposition to eating behavior disorder

\begin{tabular}{|c|c|c|c|c|c|c|}
\hline \multirow{3}{*}{ YTT-40 puanı } & \multicolumn{4}{|c|}{ Cinsiyet } & \multirow{2}{*}{\multicolumn{2}{|c|}{ Toplam $(n=33)$}} \\
\hline & \multicolumn{2}{|c|}{$K ı z(n=18)$} & \multicolumn{2}{|c|}{ Erkek $(n=15)$} & & \\
\hline & $\mathbf{n}$ & $\%$ & $\mathbf{n}$ & $\%$ & $\mathbf{n}$ & $\%$ \\
\hline 30 & 2 & 1,1 & 1 & 0,8 & 3 & 1,0 \\
\hline 31 & 2 & 2,3 & - & - & 2 & 1,2 \\
\hline 32 & - & - & 2 & 1,7 & 2 & 0,6 \\
\hline 33 & 2 & 1,1 & - & - & 2 & 0,6 \\
\hline 34 & 1 & 0,6 & 1 & 0,8 & 2 & 0,6 \\
\hline 35 & 2 & 1,1 & 2 & 2,5 & 4 & 1,5 \\
\hline 36 & 1 & 0,6 & 1 & 1,7 & 2 & 1,0 \\
\hline 39 & 2 & 1,1 & 1 & 1,7 & 3 & 1,3 \\
\hline 40 & 1 & 1,1 & - & - & 1 & 0,8 \\
\hline 41 & - & - & 3 & 2,5 & 3 & 1,0 \\
\hline 42 & 1 & 0,6 & 1 & 0,8 & 2 & 0,6 \\
\hline 43 & - & - & 1 & 0,8 & 1 & 0,3 \\
\hline 44 & 2 & 1,1 & - & - & 2 & 0,6 \\
\hline 45 & 1 & 0,6 & - & - & 1 & 0,3 \\
\hline 46 & 1 & 0,6 & 1 & 0,8 & 2 & 0,7 \\
\hline 75 & - & - & 1 & 0,8 & 1 & 0,2 \\
\hline YTT-40PuanıOrtalaması & & $3 \pm 7.96$ & & 10,95 & & $17,36 \pm 8,89$ \\
\hline
\end{tabular}


Kız öğrencilerin \% 11,9'unun ( $n=18)$, erkek öğrencilerin \%14,9'unun ( $n=15)$ YTT-40 puanı $\geq 30$ olarak tespit edilmiştir. En yüksek YTT-40 puanını (75) alan öğrencinin de erkek olduğu belirlenmiştir. YTT-40 ölçeğinden kız öğrencilerden \%9,0'u (13 kişi) 30-40 arasında, \%2,9'u (5 kişi) 41-46 arasında, erkek öğrencilerden ise \%8.2'si $(n=8) 30-40$ arasında, \%5.7'si $(n=6)$ 41-46 arasında puan almıştır (Çizelge 4). Erkek öğrencilerin yeme davranışı bozukluğuna kızlardan daha fazla yatkınlık gösterdiği tespit edilmiştir.

$\mathrm{Bu}$ noktadan hareketle, yeme bozukluğu tespit edilen öğrencilere sayısı fazla olmamakla birlikte rastlanılmıştır. Yeme bozukluğuna neden olan etmenler arasında fiziksel olarak kendine dikkat etmeme durumunun yanı sıra beslenme tutumunda göze çarpan bazı aksaklıklar not edilmiştir. Örneğin, öğrencilere yemek yerken yiyecekleri küçük parçalara bölüp bölmedikleri sorulduğunda $\% 28,1$ 'inin $(n=38)$ hiçbir şekilde bölmediği, sadece $\% 8,1^{\prime}$ inin $(n=21)$ bu hususa dikkat ettiği cevabı alınmıştır. Lokmaların mümkün olduğu kadar çiğnenerek ve küçültülerek kontrollü yenmesini mümkün kılmanın olumlu beslenme tutumlarından olduğu düşünülürse, uygulanması ne yazık ki düşük oranlarda kalmıştır. Benzer içerikte, yedikleri yiyeceklerin kalorisi hakkında bilgi sahibi olup olmadıkları sorulduğunda ise $\% 38,4$ gibi önemsenecek bir kitlenin ( $n=93$ ) hiçbir şekilde bilmediği (Şekil 3); aldıkları besinlerin ekmek, patates, pirinç gibi yüksek kalorili yiyeceklerden olmamasına dikkat etme oranlarının ise $\% 5,8(n=14)$ kadar düşük olduğu tespit edilmiştir (Şekil 4).

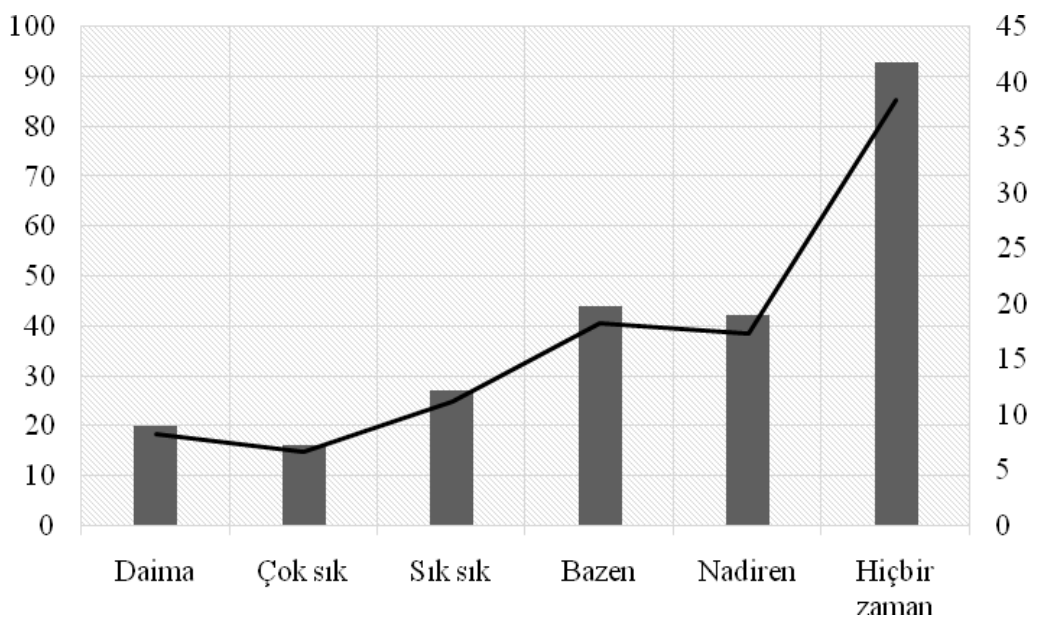

Şekil 3. Tüketilen besinlerin kalorisi hakkında bilgi düzeyi

Figure 3. Level of knowledge about the calorie of consumed foods

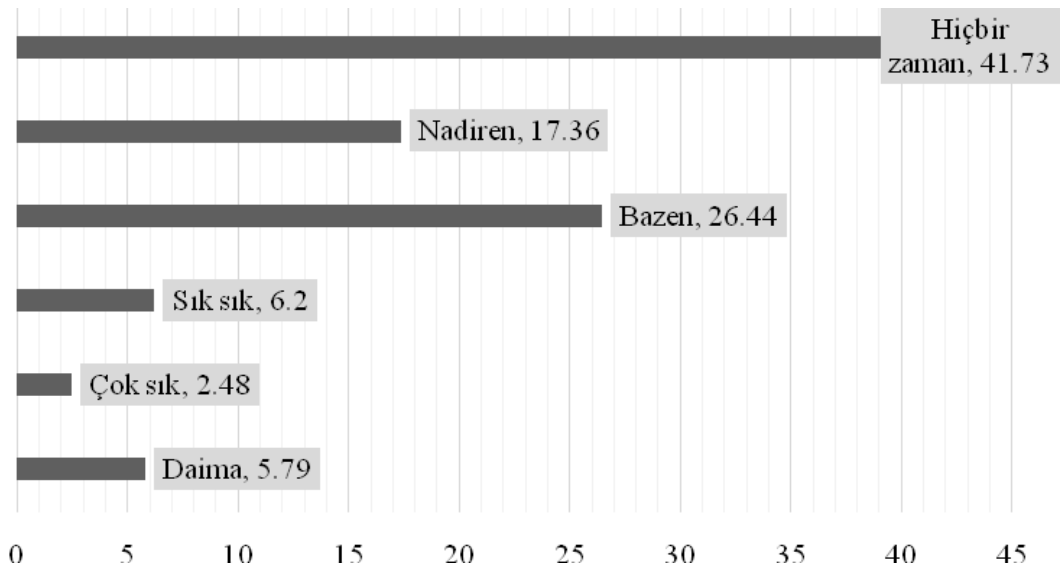

Şekil 4. Yüksek karbonhidrat içerikli besinlerin tüketilmesinde seçicilik düzeyi Figure 4. Selectivity level for high carbohydrate food consumption 
İşte burada beslenme konusunda geleneksel yemek kültürünün baskın hale getirilmesi için çalışmalar yapılmaktadır. Bu kapsamda öğrencilere geleneksel beslenmenin tanımı, ilkeleri, kültürün zenginliği ve yemek çeşitliliği hakkında eğitimler verilmiştir. Eğitim bilgilerinin anlaşııılığını ve pratiğe dökülüp dökülmediğinin ölçülmesine kadar 8 hafta bekleme süresi verilmiştir. Verilen süre sonunda analizler tekrarlanmıştır. Alınan sonuçlarda yeme bozukluğu oranında \%3,8 oranında azalma gözlemlenirken, geleneksel beslenme alışkanlıkları konusundaki farkındalığın ise $\% 28,6$ oranında artış gösterdiği dikkati çekmiştir.

\section{SONUÇ}

Çalışma kapsamında, Yaşar Üniversitesi Meslek Yüksekokulu'nda bulunan toplam 11 adet programda öğrenim gören öğrencilerin beslenme tutumları, yeme durum tespiti çalışmasını yapılmıştır. Araştırma yapılan öğrencilerde yeme bozukluğu görülüp görülmediğinin tespitine yönelik 40 sorudan oluşan YTT testi uygulanmıştır. Aynı zamanda demografik yapıları hakkında bilgi edinilmiştir. Üniversite öğrenimi gençleri erişkin hayata hazırlayan önemli bir dönemdir. Sağlık

\section{KAYNAKLAR}

Andreoli, E. T., Bennett, J. C., Carpenter, C. C. J., Plum, F. 1997.Cecil Essentials of Medicine.Fourth Edition. W.B. Saunders Company, $446 \mathrm{~s}$.

Ayaz, S., Tezcan, S. ve Akıncı, F. 2005. Hemşirelik yüksekokulu öğrencilerinin sağlı̆̆ geliştirme davranışları. Cumhuriyet Üniversitesi Hemşirelik Yüksekokulu Dergisi, 9(2): 26-34.

Baban, A. 2010. Counseling for health promation. 9.Uluslararası Katılımlı Ulusal Hemşirelik Öğrencileri Kongresi. Kongre Özet Kitabi, 20 s.

Altunışı, R., Coşkun R., Bayraktaroğlu, S., Yıldırım, E. 2007. Sosyal bilimlerde araştırma yöntemleri: SPSS uygulamalı. Istanbul, Sakarya Yayıncilik.

Baş, M., Aş̧̧, F. H., Karabudak, E., Kızıltan, G. 2005. Eating attitudes and their psychological correlates among Turkish adolescents. Adolescence, 39: 593-599.

Button E.J. and Whitehouse, A. 1981. Subclinical Anorexia Nervosa. Psychological Medicine, 11 (3): 509-510.

Cohn, L. D., Macfarlane, S., Yanez, C., Imai, W.K. 1995. Riskperception: differences between adolescents and adults. Health Psychology, 14(3): 217-222.

Garner, D.M., Garfinkel, P.E. 1979. The Eating Attitudes Test: An Index of the Symptoms of Anorexia Nervosa. Psychological Medicine, 9 (2): 273-279.

Haddad, L., Kane, D., Rajacich, D., Cameron, S. and Al-Ma'aitah, R. 2004. A Comparison of Health Practices of Canadian and Jordanian Nursing Students. Public Health Nursing, 21(1): 85-90.

Hui, W. H. C. 2002. The health-promoting lifestyles of undergraduate nurses in Hong Kong. J Prof Nurs, 18(2): 101-111. düzeyini iyileştirmeye yönelik yaşam becerileri ve pozitif yaşam tarzı arasında yeme davranışları önemli bir yer tutmaktadır. Bu kapsamda yapılan incelemelerde kadınlarda, özgüven eksikliği görülen bireylerde, diyet yapan öğrencilerde yeme bozukluğu davranışı riskinin arttığı tespit edilmiştir. Sayının erkeklere nazaran kadınlarda fazla çıkmasının belirleyici nedenlerinin bir tanesi izlenilen çeşitli diyet programları olmuştur. Bu anlamda, sağlığın bozulma riskini beraberinde getiren kulaktan dolma bilgiler ile diyet yapma anlayışının yıkılacağı, yerine sağlıkı beslenme ilkelerinin benimsenmesi gerektiği bilinçlendirme ve farkındalık oluşturma eğitimlerinin yapılması ya da sayısının arttırılması gereği doğmuştur. Aynı zamanda, hem vücudu zinde tutmanın hem de sağlıklı besinlerle donatılmış gıdaların çeşitlendirildiği geleneksel mutfak kültürü zihniyetinin arttırılması ihtiyacı gündeme gelmiştir. Çünkü beslenme kurallarına dikkat eden bireylerin çoğunluklu olarak geleneksel beslenme ilkelerine uygun hareket ettikleri tespit edilmiştir, bu nedenle edinilen ilkelerin kültür mirasının korunması cephesine de hizmet etmesi hem üretici hem de tüketicilerin yararına olacaktır.
Karasar, N. 2004. Bilimsel Araştırma Yöntemi. Ankara, Nobel YayınDağııım, s. 24.

Menteş, E., Menteş, B., Karacabey, K. 2011. Adölesan dönemde obezite ve egzersiz. İnsan Bilimleri Dergisi, 8: 963-977.

Öğel B. 1991. Türk Kültür Tarihine Giriş. Kültür Bakanlığı kültür eserleri, 2(46): 3-62.

Öztürk, M.O. 2004. Ruh sağlığı ve bozuklukları. Nobel Tıp Kitap evi Yayınları, Ankara, pp. 472-476.

Patton, G.C., Johnson-Sabire, T., Wood, K., Mann, A.H., Wakeling A. 1990. Abnormal Eating Attitudes in London School Girls a Perspective Epidemiological Study: Outcome at Twelve Months Follow-up. Psychological Medicine, 20 (2): 383-394.

Polat, A., Yücel, B., Genç, A., Meteris, H. 2005. Bir grup üniversite öğrencisinde yeme davranışı özellikleri: Bir ön çalışma. Nöropsikiyatri Arşivi, 42: 5-9.

Sucakl1, M. H. 2015. Alcohol and Substance Use among Children and Adolescents in an Orphanage. Konuralp Medical Journal, 7 (1): 23-27.

Sapmaz, K. ve Yercan, M. 2015. Tüketicilerin Market Markalı ve Üretici Markalı Gida Ürünü Tercihlerinin Analizi: İzmir İli Örneği. Journal of Agriculture Faculty of Ege University, 52(3): 317-325.

Savaşır, I. ve Erol, N. 1989. Yeme Tutum Testi: Anoreksi Nervoza Belirtileri Indeksi. Psikoloji Dergisi, 7(23): 19-25.

Vardar, E, Erzengin, M. 2011. Ergenlerde yeme bozukluklarının yaygınlığı ve psikiyatrik eştanıları: iki aşamalı toplum merkezli bir çalışma. Türk Psikiyatri Dergisi, 22: 205-212. 